\title{
Dosimetric Evaluation of 3-Dimensional Conformal Radiotherapy Technique in Postoperative Patients with Gastric Carcinoma: When Is IMRT Really Needed?
}

\author{
Rakesh Kapoor, Srinivasa GY, Namrata Das, Chinna Babu Dracham, Divya \\ Khosla, Arun S Oinam
}

Department of Radiotherapy \& Oncology, Post Graduate Institute of Medical Education and Research, Chandigarh, India.

\begin{abstract}
Background and purpose: Adjuvant Chemoradiotherapy is the standard of care for postoperative gastric cancers with high risk features. The purpose of the current study is to do a dosimetric analysis in the postoperative setting by using 3-Dimensional Conformal Radiotherapy (3D-CRT) to a total dose of 45 Gy in 25 fractions over 5 weeks. A subsequent comparison with the 3D-CRT and IMRT of other published data is presented. Materials and Methods: Sixty postoperative patients who underwent radiation with 3D-CRT technique were included in this analysis. All patients received concurrent 5-Flurouracil or Capecitabine chemotherapy along with radiation. Radiation plans were analysed in terms of PTV coverage, conformity index (CI), homogeneity index (HI), organs at risk (OARs) and dose volume histogram (DVH) parameters. Results: DVH statistics for PTV: Dmean was 45.2 \pm 0.8 Gy, D98 was $42.9 \pm 1$ Gy, D95 was $43.4 \pm 0.8$ Gy, and D2 was 47.7 \pm 1.1 Gy. Mean CI for all plans was $1.23 \pm 0.43$ and HI was $1.09 \pm 0.03$. DVH parameters for OARs: right kidney, Dmean $=11.9 \pm 5.1 \mathrm{~Gy}$, V18 was $21.5 \pm 13.8 \%$, V15 was $27.2 \pm 14.9 \%$ and left kidney, Dmean was $17.7 \pm 5.8$ Gy, V18 was $33.5 \pm 13.8 \%$, V15 was $43.2 \pm 15.5 \%$. Dmean for liver was $27.7 \pm 6.4$ Gy and V20 was $69.2 \pm 15.8 \%$. D195cc for the bowel bag was $36.3 \pm 10.8 \mathrm{~Gy}$. Conclusion: The results of this study and subsequent comparison with existing literature suggests that 3D-CRT provides adequate homogenous target volume dose coverage and OAR protection, comparable to IMRT. More than the radiotherapy technique, it was the anastomotic site and the tumor location that determined the OAR doses.
\end{abstract}

Keywords: Gastric cancer- Adjuvant 3D-CRT- DVH- conformity index

\section{Introduction}

Stomach cancer is the fifth most common cancer in the world (5.7\% of all new cases) and the third most common cause of cancer related death $(8.2 \%$ of all cancer deaths) [1]. India has a low incidence of stomach cancer compared to world statistics and is the fifth most common cancer in India. The estimated incidence of gastric cancer in India for the year 2018 was 5\% (57,394 cases) and about 38,818 new gastric cancer cases were estimated to have occurred in males [2]. Partial or total gastrectomy is the mainstay of treatment in the management of stomach cancer [3]. In the majority of cases, treatment with surgery alone is not satisfactory and the 5-years survival depends on tumour stage and lymph nodal status. Loco-regional recurrence is the major problem in $80-85 \%$ of patients [4-5]. Since the introduction of SWOG/INT0116 trial in 2001, adjuvant concurrent chemoradiotherapy (CRT) became the standard of care for gastric cancer [6]. The benefits of adjuvant CRT was extended even for patients with D2 dissection [7]. However, post-operative radiotherapy significantly increases toxicities compared to surgery alone [6]. This has been minimised with the advent of newer technologies like 3D-CRT and IMRT. Superiority of IMRT over 3D-CRT has not been clearly established unlike few other sites [8-9]. The purpose of

Corresponding Author:

Dr. Srinivasa G Y

Department of Radiotherapy \& Oncology, Post Graduate Institute of Medical Education and Research, Chandigarh, India.

Email: drsrinivasagowda@gmail.com 
the present study was to do a dosimetric analysis of the doses received in post-operative setting by using 3D-CRT to a total dose of 45 Gy in 25 fractions over five weeks with concurrent chemotherapy. A subsequent comparison with the existing 3D-CRT and IMRT literature was done.

\section{Materials and Methods}

This retrospective analysis on dosimetric data in post-operative carcinoma stomach was carried out at the Department of Radiotherapy and Oncology in a multispecialty tertiary care centre in India after informed consent. Being a retrospective dosimetric analysis of patients treated as per institutional protocol, additional ethical clearance was not sought. Case records of all patients with carcinoma stomach (adenocarcinoma and signet ring cell carcinoma) registered in the department between January 2012 and December 2015 were analysed. Out of 156 cases of primary gastric cancer, only 93 $(60 \%)$ of the cases were histopathologically confirmed to have adenocarcinoma and signet ring cell carcinoma. Out of these, the 60 patients who underwent radical surgery followed by post - operative radiotherapy have been included in this analysis and the rest who received palliative treatment were omitted. All patients received concurrent chemotherapy using 5-FU or capecitabine based regimen. Staging was done according to AJCC $7^{\text {th }}$ edition staging system [10].

\section{Radiotherapy Planning}

The post-operative patients of carcinoma of stomach were selected for this dosimetric analysis of the doses received by PTV and OARs using 3D-CRT. All patients underwent total or subtotal gastrectomy with D1 or D2 lymph-nodal dissection. Planning CT scans were taken with patients in supine position using multislice CT scanner with a slice thickness of $2.5 \mathrm{~mm}$ (GE healthcare technologies, Wankesha, WI, USA). The images were then transferred to EclipseTM treatment planning system (v.8.6, Varian associates, Palo, Alto, CA, USA). Contouring was done as per Tepper and Gunderson guidelines [10-11]. The clinical target volume (CTV) included both post-operative tumour bed and regional lymphatic drainage. The nodal CTV included nodes in the para-aortic (PA), celiac axis, porta hepatis and superior mesenteric artery (SMA) group. All lymph nodal groups were contoured according to the guidelines be Tepper et al [10]. The PA lymph-nodal volume was delineated by giving differential margin to the aorta from thoracic (T11) to lumbar (L2) vertebrae, (i.e. $2.5 \mathrm{~cm}$ right side, $2 \mathrm{~cm}$ anterior, $1.2 \mathrm{~cm}$ left side, and 0.2 $\mathrm{cm}$ posterior), $1 \mathrm{~cm}$ symmetric margin was given to portal vein (from origin of portal vein to porta-hepatis), celiac artery (from origin of celiac axis to its first bifurcation) and superior mesenteric artery (from its origin to $1 \mathrm{~cm}$ ) (Figure 1). The CTV tumour included the tumour bed, remaining stomach and anastomotic site. Both CTV nodal and CTV tumour were dependent on the primary location of the tumour, pathological T-stage and nodal stage. The CTV total was made by joining both CTV nodal and tumour with the help of Boolean apparatus. PTV was contoured by giving $1 \mathrm{~cm}$ symmetric margin around CTV total. OARs including liver, both kidneys, spinal cord, heart, and small bowel were contoured. 3D-CRT plans were generated by using one anterior and two lateral fields with appropriate wedges (Figure 2) with $6 \mathrm{MV}$ photons and treatment was executed by a linear accelerator. A total dose of 45 Gy in 25 fractions were prescribed to the PTV. Plans were optimised whenever required to deliver the prescribed dose to more than $95 \%$ of PTV. Dose volume histograms (DVH) were generated and evaluated for all the OARs before delivering the treatment. Evaluation of dosimetric data of the target volumes and OARs was done using Quantitative Analysis of Normal Tissue Effects in Clinics (QUANTEC) parameters [12].

All 3D-CRT plans were analysed in terms of PTV coverage, conformity index (CI), homogeneity index (HI), and OAR dose volume parameters. Several definitions of $\mathrm{CI}$ and HI are available but we used the RTOG definitions to calculate the CI and HI.

Conformity index (RTOG definition) $=$ Reference isodose volume / target volume

Homogeneity index $=$ maximum isodose in the target / reference isodose

In an ideal scenario the CI should be equal to 1 and HI should be $<2$. CI less than 1 indicates that the target volume is not adequately irradiated and a value greater than 1 signifies that the irradiated volume is greater than the target volume.

\section{Statistics}

Statistical analysis was done with the Statistical Program for Social Sciences (SPSS v23, IBM Corp, USA). Descriptive analysis was done for the dosimetric and demographic data. Summary of statistics including mean, range, and standard deviation were obtained.

\section{Results}

\section{Patient and treatment characteristics}

The median age of patients in our study was 52 years (22-75 years). Most of them were males (33 patients, 55\%). Most of the patients were smokers $(60 \%)$ and occasional

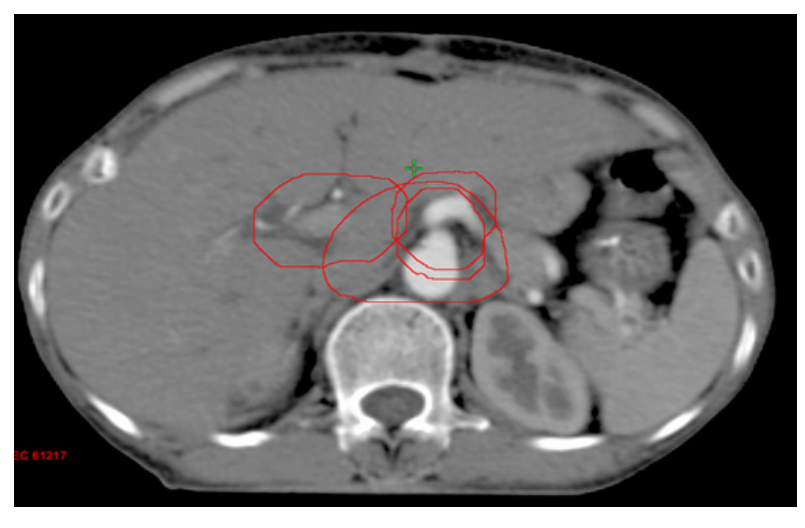

Figure 1. CTV NODAL Contouring; $1 \mathrm{~cm}$ Symmetric Margin Around Portal Vein, Celiac Artery, Superior Mesenteric Artery; Differential Margin Around Aorta, $2.5 \mathrm{~cm}$ right, $2 \mathrm{~cm}$ Anterior, $1.2 \mathrm{~cm}$ Left, and $0.2 \mathrm{~cm}$ Posterior 
Table 1. Patient and Disease Characteristics

\begin{tabular}{lcc}
\hline Characteristic & Number & Percentage (\%) \\
\hline Gender & 33 & $55 \%$ \\
Male & 27 & $45 \%$ \\
Female & $52(22-75)$ & \\
Median age (years) & 36 & $60 \%$ \\
Smoker & 33 & $55 \%$ \\
Alcoholics & & \\
Surgery & 54 & $90 \%$ \\
Sub-total gastrectomy & 6 & $10 \%$ \\
Total gastrectomy & & \\
Lymph-node dissection & 40 & $66 \%$ \\
D1 $^{\text {a }}$ & 20 & $33 \%$ \\
D2 $^{\mathrm{b}}$ & & \\
\hline
\end{tabular}

D1 lymph node dissection, stations 1 to 6 ; along the greater and lesser curvature of stomach; ${ }^{b} \mathrm{D} 2$ lymph node dissection, D1 and stations 7 to 11; along left gastric artery, common hepatic artery, celiac trunk, and splenic artery.

alcoholics $(55 \%)$. Five percent of the patients had a family history of malignancy. The common presenting symptoms were loss of appetite, upper abdominal pain and loss of weight. Most of the patients underwent sub-total gastrectomy (90\%) with D1 lymph-node dissection (66\%) or D2 lymph-node dissection (33\%). Adenocarcinoma (intestinal type) was the most common post-operative histopathological variant. All patients underwent post-operative radiotherapy to a total dose of 45 Gy in 25 fractions over 5 weeks using 3D-CRT (Table 1).

\section{Dosimetric parameters of PTV}

The mean PTV volume was $848.6 \pm 337 \mathrm{cc}$, Dmean was $45.2 \pm 0.8 \mathrm{~Gy}$, D98 was $42.9 \pm 1 \mathrm{~Gy}$, D95 was $43.4 \pm 0.8 \mathrm{~Gy}$, D50 was $45.2 \pm 0.7 \mathrm{~Gy}$, D5 was $47.3 \pm 1.0 \mathrm{~Gy}$ and D2 was $47.7 \pm 1.1 \mathrm{~Gy}$. Mean CI for all plans was $1.23 \pm 0.43$ and $\mathrm{HI}$ was $1.09 \pm 0.03$ (Table 2).

\section{Dosimetric parameters of OARs}

DVH parameters for OARs; right kidney Dmean was $11.9 \pm 5.1 \mathrm{~Gy}, \mathrm{~V} 18$ was $21.5 \pm 13.8 \%$, V15 was $27.2 \pm 14.9 \%$, V13 was $31.7 \pm 15.7 \%$ and left kidney Dmean was $17.7 \pm 5.8$ Gy, V18 was $33.5 \pm 13.8 \%$, V15 was $43.2 \pm 15.5 \%$, V13 was $59 \pm 15.6 \%$ (Figure 3 ). Dmean for liver was $27.7 \pm 6.4 \mathrm{~Gy}$

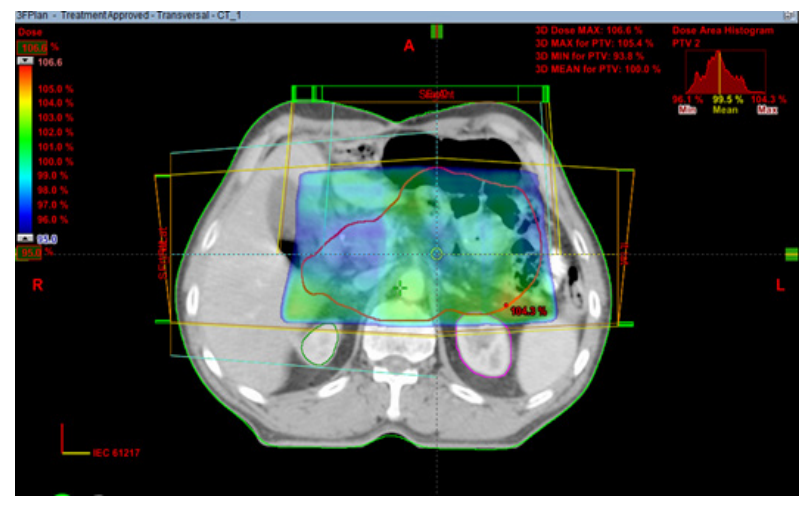

Figure 2. PTV with 95\% Dose Colour Wash; 3DCRT Plan Showing Three Radiation Portals, Anterior; Right Lateral, and Left Lateral Fields

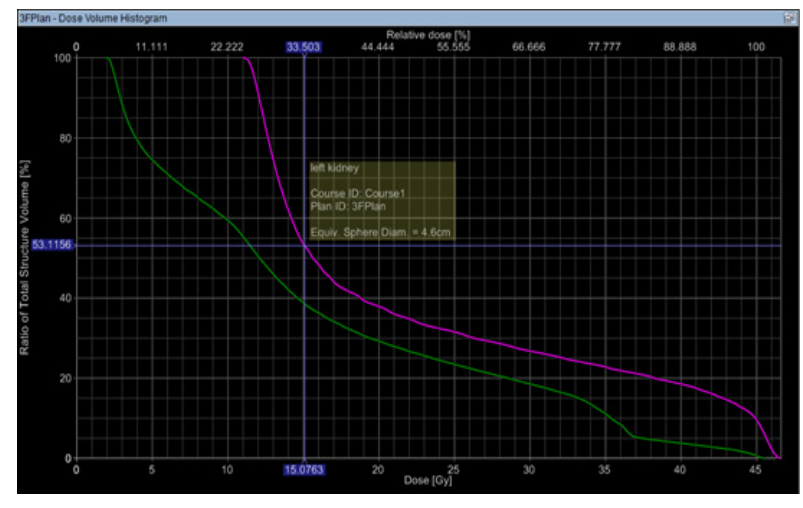

Figure 3. Dose Volume Histogram Showing V15 for Left Kidney and Right Kidney

and V20 was $69.2 \pm 15.8 \%$. D195cc for the bowel bag was $36.3 \pm 10.8 \mathrm{~Gy}$, Dmax was $48.7 \pm 1.4 \mathrm{~Gy}$, and V45 was $29.2 \pm 9.8 \%$. Dmax for spinal cord was $30.0 \pm 10.8 \mathrm{~Gy}$. Dmean for the heart was $4.5 \pm 0.84 \mathrm{~Gy}$ (Table 3).

\section{Discussion}

Partial or total gastrectomy along with the D1 or D2 lymph-node dissection is the mainstay of treatment in the management of stomach cancer. Loco-regional recurrence is the major problem in patients treated with surgery alone necessitating various attempts at improving survival using

Table 2. Dosimetric Parameters of the Planning Target Volume (PTV)

\begin{tabular}{lcc}
\hline PTV & Mean \pm Standard deviation & Range \\
\hline Volume $^{\mathrm{a}}$ & $848.6 \pm 337.0$ & $338-2610$ \\
Dmean $^{\mathrm{b}}$ & $45.2 \pm 0.8$ & $41.3-47.0$ \\
D98 $^{\mathrm{b}, \mathrm{c}}$ & $42.9 \pm 1.0$ & $39.1-44.6$ \\
D95 $^{\mathrm{b}}$ & $43.4 \pm 0.8$ & $39.5-44.8$ \\
D50 $^{\mathrm{b}}$ & $45.2 \pm 0.7$ & $41.8-47.3$ \\
D5 $^{\mathrm{b}}$ & $47.3 \pm 1.0$ & $44.8-49.7$ \\
D2 $^{\mathrm{b}}$ & $47.7 \pm 1.1$ & $45.6-50.7$ \\
Confomity index (CI) & $1.23 \pm 0.43$ & $0.70-2.30$ \\
Homogenity index(HI) & $1.09 \pm 0.03$ & $1.04-1.20$ \\
\hline
\end{tabular}

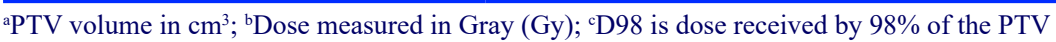


Table 3. Dosimetric Parameters of the OARs

\begin{tabular}{|c|c|c|}
\hline Organ at risk & Mean \pm Standard deviation & Range \\
\hline \multicolumn{3}{|l|}{ Right kidney } \\
\hline Dmeana & $11.9 \pm 5.1$ & $2.2-22.8$ \\
\hline $\mathrm{V} 18^{\mathrm{b}}$ & $21.5 \pm 13.8$ & $0-55$ \\
\hline V15 & $27.2 \pm 14.9$ & $0-61$ \\
\hline V13 & $31.7 \pm 15.7$ & $0-65$ \\
\hline \multicolumn{3}{|l|}{ Left kidney } \\
\hline Dmean ${ }^{\mathrm{a}}$ & $17.7 \pm 5.8$ & $8.5-45.6$ \\
\hline $\mathrm{V} 18^{\mathrm{b}}$ & $33.5 \pm 13.8$ & $5.7-61.0$ \\
\hline V15 & $43.2 \pm 15.5$ & $13.5-84.0$ \\
\hline V13 & $59.0 \pm 15.6$ & $21.6-85$ \\
\hline \multicolumn{3}{|l|}{ Heart } \\
\hline Dmean $^{\mathrm{a}}$ & $4.5 \pm 0.84$ & $3.7-8.5$ \\
\hline \multicolumn{3}{|l|}{ Liver } \\
\hline Dmean $^{\mathrm{a}}$ & $27.7 \pm 6.4$ & $9.0-39.9$ \\
\hline V20 & $69.2 \pm 15.8$ & $27-95$ \\
\hline \multicolumn{3}{|l|}{ Bowel Bag } \\
\hline $\operatorname{Dmax}^{\mathrm{a}}$ & $48.7 \pm 1.4$ & $44.7-52$ \\
\hline V45 & $29.2 \pm 9.8$ & $13.5-58.8$ \\
\hline $\mathrm{D} 195 \mathrm{cc}^{\mathrm{a}}$ & $36.3 \pm 6.7$ & $23.9-48.0$ \\
\hline \multicolumn{3}{|l|}{ Spinal cord } \\
\hline $\operatorname{Dmax}^{\mathrm{a}}$ & $30.0 \pm 10.8$ & Jul-48 \\
\hline
\end{tabular}

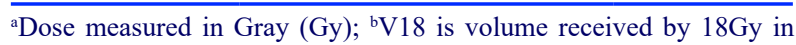
percentage

radiotherapy and chemotherapy both before and after surgery [5-11]. Adjuvant CRT became the standard of care since the introduction of SWOG/INT0116 trial [6]. The presence of OARs like spinal cord, liver, small bowel and bilateral kidneys limit the delivery of radiation dose to the post-operative tumour bed, especially with 2D-conformal radiotherapy where antero-posterior and postero-anterior (AP-PA) radiation portals were used. The high rates of Grade 3 toxicities seen in this seminal trial were subsequently minimized with the replacement of conventional treatment techniques by 3D-CRT and IMRT. With the introduction of 3D-CRT, dose to the OARs could be minimized with adequate delivery of dose to the tumour bed and nodal basin [4-12].

In our study, by using the standard RTOG tools, both $\mathrm{HI}$ and CI were within the range of reported IMRT data [13]. In a study by $\mathrm{Li} \mathrm{Z}$ et al, the author compared dosimetric parameters of 5 field intensity-modulated radiotherapy (5F-IMRT), 7F-IMRT, single-arc volumetric modulated arc therapy (SA-VMAT) and double arc (DA)VMAT [12]. All plans were made with the prescription dose of 50.4 Gy in 28 fractions. CI was $0.86 \pm 0.02$ in both 5F-IMRT and 7F-IMRT planning's, $0.83 \pm 0.03$ for SA-VMAT, and $0.87 \pm 0.03$ for DA-VMAT planning. CI was better with the IMRT and ARC therapy compared to 3D-CRT planning in the current study due to the forward planning of 3D-CRT.

Kidney is a radiosensitive organ and abdominal or pelvic radiotherapy leads to damage to one or both the kidneys [14]. For bilateral kidneys, V $20<32 \%$, mean dose $<15-18 \mathrm{~Gy}, \mathrm{~V} 12<55 \%$ is recommended to get $<5 \%$ of radiation induced kidney damage [15-16]. In the present study, mean dose to the left kidney was higher than the right kidney, the primary reason being that the left kidney in most of the patients was located within the target volume and tumor bed was anterior to the left kidney. However, the doses were comparable to that reported in various studies as outlined in Table 4 by both IMRT and 3D-CRT. Therefore, location of the post-operative bed rather than the technique appeared to be the primary limiting factor. Alani et al. defined separate high and low dose kidney instead of laterality to incorporate this concept.

Liver is a parallel organ, and the radiation induced liver damage (RILD) is found to correlate with the volume and dose of radiation received by the normal liver tissue. The incidence of RILD is dependent on the mean dose to the normal liver tissue with models predicting no cases of RILD with a mean liver dose $<31$ Gy [20]. In the present study, mean dose to the liver was $27.7 \pm 6.4$ Gy and V20 was $69.2 \pm 15.8$ which were within the tolerable limit for the normal liver tissue. Though mean doses to the liver were lower with IMRT as reported by $\mathrm{Li} \mathrm{Z}$ et al [12] and Minn et al. [8], 3D-CRT planning yielded values well within tolerance limits.

Severe gastro-intestinal (GI) toxicities are the main dose limiting factor in case of abdominal irradiation. In a comparison study of IMRT and 3D-CRT for adjuvant treatment of gastric cancer by Minn AY et al, grade 2 or higher GI toxicity was found to be similar between IMRT and 3D-CRT patients (61.2\% and 61.5\% respectively) and V45 for the bowel space is $106.2 \mathrm{cc}$, Dmax is $50.5 \mathrm{~Gy}$ for IMRT planning [18]. In another study by Liu GF et al, acute GI toxicities were found to be $56 \%$ and $54 \%$ for IMRT and 3D-CRT respectively [21]. Li Z et al showed that the Dmean for small intestine was 17.19 $\pm 6.26 \mathrm{~Gy}$ for 5F-IMRT, 16.50 \pm 5.76 Gy for 7F-IMRT, 18.01 \pm 6.34 Gy for SA-VMAT, 16.90 \pm 5.92 Gy for DA-VMAT [13].

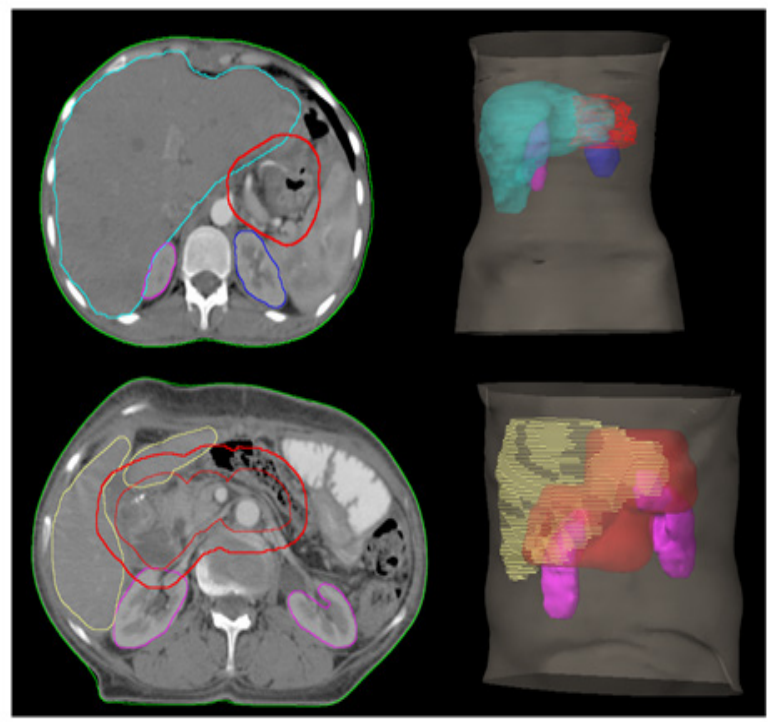

Figure 4. Position of CTV and OARs 
In the present study, Dmax for the bowel bag is $48.7 \pm 1.4$ Gy, V45 is $29.2 \pm 9.8 \%$, and D $195 \mathrm{cc}$ is $36.3 \pm 6.7$ Gy which showed that the doses were comparable to the above mentioned studies.

For individual patients more than the radiotherapy technique it was the position of the anastomotic site which influenced high OAR doses (kidney and liver). The anastomotic sites and DVHs comparing kidney doses of an individual patient are shown in Figure 4.

Limitation of the current study are its retrospective nature and there is no direct comparison of 3D-CRT planning with the IMRT planning for the same set of patients.

In conclusion, results of the study suggest that there is a challenge in achieving the Organ at Risk (OAR) constraints in respect to bowel bag and mean doses achieved for left kidney in patients who had undergone D1 lymphadenectomy. It was also observed that inclusion of postoperative site was having changing position depending upon patient to patient which further led to difficulty in achieving constraints. Some of these patients may favour IMRT based treatment to have better dose delivery.

In the current study we found that post-operative 3D-CRT in cases of carcinoma stomach is acceptable in terms of target volume coverage and homogeneity. The strength of our current study is that it contains detailed dosimetric analysis in terms of physical parameters of target volume, HI, CI and OAR doses in a homogenous group of post-operative cases of carcinoma of stomach. In a country like India where we have increased patient load, we can spend less time on machine using 3D-CRT. Based on the result we could conclude that 3D-CRT offers good coverage of target volumes at the same time sparing the critical surrounding organs.

\section{References}

1. [cited 23 Feb 2020]. Available: https://gco.iarc.fr/today/data/ factsheets/cancers/7-Stomach-fact-sheet.pdf.

2. [cited 23 Feb 2020]. Available: https://gco.iarc.fr/today/data/ factsheets/populations/356-india-fact-sheets.pdf.

3. Dupont JB, Lee JR, Burton GR, Cohn I. Adenocarcinoma of the stomach: Review of 1,497 cases. Cancer. 1978 03;41(3):941-947. https://doi.org/10.1002/10970142(197803)41:3<941::aid-cncr2820410323>3.0.co;2-m

4. Ringash J, Khaksar S, Oza A, Couture J, Japp B, Moore M, Siu L, Hedley D, Swallow C, Wong S, Cummings B, Kim J, Wong R, Brierley J. Post-operative radiochemotherapy for gastric cancer: adoption and adaptation. Clinical Oncology. 2005 04;17(2):91-95. https://doi.org/10.1016/j. clon.2004.09.017

5. Gunderson LL, Sosin H. Adenocarcinoma of the stomach: Areas of failure in a re-operation series (second or symptomatic look) clinicopathologic correlation and implications for adjuvant therapy. International Journal of Radiation Oncology*Biology*Physics. 1982 01;8(1):1-11. https://doi.org/10.1016/0360-3016(82)90377-7

6. Macdonald JS, Smalley SR, Benedetti J, Hundahl SA, Estes NC, Stemmermann GN, Haller DG, Ajani JA, Gunderson LL, Jessup JM, Martenson JA. Chemoradiotherapy after Surgery Compared with Surgery Alone for Adenocarcinoma of the Stomach or Gastroesophageal Junction. New England 
Journal of Medicine. 200109 06;345(10):725-730. https:// doi.org/10.1056/nejmoa010187

7. Kim S, Lim DH, Lee J, Kang WK, MacDonald JS, Park CH, Park SH, Lee S, Kim K, Park JO, Kim WS, Jung CW, Park YS, Im Y, Sohn TS, Noh JH, Heo JS, Kim YI, Park CK, Park K. An observational study suggesting clinical benefit for adjuvant postoperative chemoradiation in a population of over 500 cases after gastric resection with D2 nodal dissection for adenocarcinoma of the stomach. International Journal of Radiation Oncology*Biology*Physics. 2005 Dec;63(5):1279-1285. https://doi.org/10.1016/j. ijrobp.2005.05.005

8. Minn AY, Hsu A, La T, Kunz P, Fisher GA, Ford JM, Norton JA, Visser B, Goodman KA, Koong AC, Chang DT. Comparison of intensity-modulated radiotherapy and 3-dimensional conformal radiotherapy as adjuvant therapy for gastric cancer. Cancer. 201005 13;116(16):3943-3952. https://doi.org/10.1002/cncr.25246

9. Alani S, Soyfer V, Strauss N, Schifter D, Corn BW. Limited Advantages of Intensity-Modulated Radiotherapy Over 3D Conformal Radiation Therapy in the Adjuvant Management of Gastric Cancer. International Journal of Radiation Oncology*Biology*Physics. 2009 06;74(2):562-566. https:// doi.org/10.1016/j.ijrobp.2008.09.061

10. Edge SB, Compton CC. The American Joint Committee on Cancer: the 7th Edition of the AJCC Cancer Staging Manual and the Future of TNM. Annals of Surgical Oncology. 2010 02 24;17(6):1471-1474. https://doi.org/10.1245/s10434010-0985-4

11. Foo M. Adjuvant therapy for gastric cancer: Current and future directions. World Journal of Gastroenterology. 2014;20(38):13718. https://doi.org/10.3748/wjg.v20. i38.13718

12. LI Z, ZENG J, WANG Z, ZHU H, WEI Y. Dosimetric comparison of intensity modulated and volumetric arc radiation therapy for gastric cancer. Oncology Letters. 2014 07 18;8(4):1427-1434. https://doi.org/10.3892/ol.2014.2363

13. Shaw E, Kline R, Gillin M, Souhami L, Hirschfeld A, Dinapoli R, Martin L. Radiation therapy oncology group: Radiosurgery quality assurance guidelines. International Journal of Radiation Oncology*Biology*Physics. 1993 Dec;27(5):1231-1239. https://doi.org/10.1016/03603016(93)90548-a

14. Cassady J. Clinical radiation nephropathy. International Journal of Radiation Oncology*Biology*Physics. 1995 03;31(5):1249-1256. https://doi.org/10.1016/03603016(94)00428-n

15. Marks LB, Yorke ED, Jackson A, Ten Haken RK, Constine LS, Eisbruch A, Bentzen SM, Nam J, Deasy JO. Use of Normal Tissue Complication Probability Models in the Clinic. International Journal of Radiation Oncology*Biology*Physics. 2010 03;76(3):S10-S19. https://doi.org/10.1016/j.ijrobp.2009.07.1754

16. Bentzen SM, Constine LS, Deasy JO, Eisbruch A, Jackson A, Marks LB, Ten Haken RK, Yorke ED. Quantitative Analyses of Normal Tissue Effects in the Clinic (QUANTEC): An Introduction to the Scientific Issues. International Journal of Radiation Oncology*Biology*Physics. 2010 03;76(3):S3S9. https://doi.org/10.1016/j.ijrobp.2009.09.040

17. Milano MT, Garofalo MC, Chmura SJ, Farrey K, Rash C, Heimann R, Jani AB. Intensity-modulated radiation therapy in the treatment of gastric cancer: early clinical outcome and dosimetric comparison with conventional techniques. The British Journal of Radiology. 2006 06;79(942):497-503. https://doi.org/10.1259/bjr/43441736

18. Zhang T, Liang Z, Han J, Bi J, Yang Z, Ma H. Double-arc volumetric modulated therapy improves dose distribution compared to static gantry IMRT and 3D conformal radiotherapy for adjuvant therapy of gastric cancer. Radiation Oncology. 201505 19;10(1). https://doi.org/10.1186/ s13014-015-0420-x

19. Murthy K, Shukeili K, Kumar S, Davis C, Chandran R, Namrata S. Evaluation of dose coverage to target volume and normal tissue sparing in the adjuvant radiotherapy of gastric cancers: 3D-CRT compared with dynamic IMRT. Biomedical Imaging and Intervention Journal. 2010 07;6(3). https://doi.org/10.2349/biij.6.3.e29

20. Dawson LA, Normolle D, Balter JM, McGinn CJ, Lawrence TS, Ten Haken RK. Analysis of radiation-induced liver disease using the Lyman NTCP model. International Journal of Radiation Oncology*Biology*Physics. 2002 07;53(4):810-821. https://doi.org/10.1016/s03603016(02)02846-8

21. Liu GF, Bair RJ, Bair E, Liauw SL, Koshy M. Clinical Outcomes for Gastric Cancer following Adjuvant Chemoradiation Utilizing Intensity Modulated versus ThreeDimensional Conformal Radiotherapy. de Mello RA. PLoS ONE. 201401 09;9(1):e82642. https://doi.org/10.1371/ journal.pone. 0082642

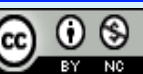

This work is licensed under a Creative Commons AttributionNon Commercial 4.0 International License. 